\title{
Risky Sexual Behavior and Associated Factors Among High School Youth in Pawe Woreda Benishangul Gumuz Region
}

\author{
Mulatu Agajie ${ }^{1,2}$, Tefera Belachew ${ }^{2}$, Tizta Tilahun ${ }^{2}$, Muluwas Amentie $^{3}$ \\ ${ }^{1}$ Department of Public Health, Pawie College of Health Science, Benishangul Gumuz Regional Health Bureau, Assosa, Ethiopia \\ ${ }^{2}$ Department of Population and Family Health, College of Public Health and Medical Sciences, Jimma University, Jimma, Ethiopia \\ ${ }^{3}$ Department of Nursing, Faculty of Health Sciences, Assosa University, Assosa, Ethiopia
}

\section{Email address:}

mulatu14@yahoo.com (M. Agaje), tefera_belachew@yahoo.com (T. Belachewu), tiztatilahun@yahoo.com (T. Tilahun), muluwas12@gmail.com (M. Amentie)

\section{To cite this article:}

Mulatu Agajie, Tefera Belachew, Tizta Tilahun, Muluwas Amentie. Risky Sexual Behavior and Associated Factors Among High School Youth in Pawe Woreda Benishangul Gumuz Region. Science Journal of Clinical Medicine. Vol. 4, No. 4, 2015, pp. 67-75.

doi: $10.11648 /$ j.sjcm.20150404.11

\begin{abstract}
Background: Youths's sexual behaviour affects their physical, psychological and social well-being leading to death. Youth are at high risk of Human Immune Virus (HIV) and Sexual Transmitted Infection (STI) despite high level of knowledge about HIV/STI. Objective: to assess risky sexual behaviour and associated factors among high school youth $15-24$ years. Methods: A cross-sectional study design was employed using a pre-tested self-administered questionnaire and supplemented by focus group discussion which conducted from May $10^{\text {th }}$ to $20^{\text {th }}, 2012 \mathrm{G}$.C among high school youth in Pawe Woreda, Northwest Ethiopia. Bivariate and multivariate analyses were employed. A total of 374 youth were selected using simple random sampling method. The data were analyzed using SPSS for windows version 16.0. Descriptive statists, bivariate and multivariable logistic regression analyses were performed after cleaning the data. Statistical significance was declared at $\mathrm{P}<0.05$. Results: Out of the study subjects; 90 (24.1\%) respondents were sexually active. Among the sexually active students: $37(41.1 \%)$ reported ever use of condom, 5.5\% reported sexual contact with commercial sex workers and $26(35.1 \%)$ reported having more than two sexual partner. Consistent use of condom was reported only by $16(43.2 \%)$. Seventy four (82.2\%) had risky sexual behavior. Only $24(26.7 \%)$ reported high chance of acquiring Human Immune Virus (HIV) and Sexual Transmitted Infection (STI). Multivariable logistic regression analyses showed that being in 18-24 age group (AOR=3.279 [95\% CI: 1.79, 6.008]) and drinking alcohol $(\mathrm{AOR}=9.1$ [95\% CI: 2.517, 32.9]) were associated with risky sexual behaviour. Conclusion: Considerable amount of school youth had started early sexual activity and have developed risky sexual behaviour that might predispose them to different sexual and reproductive health problems. Delaying sexual initiation and reducing risky sexual behaviour among youth can be achieved through well designed sexual education programs at earlier life in school.
\end{abstract}

Keywords: Risky Sexual Behaviour, Associate Factors, School Youth, Pawe, Benishangul Gumuz

\section{Introduction}

According to the World Health Organization (WHO) "adolescents" cover the age of 10 to 19 years; "youths" are defined as belonging to the age group of 15 to 24 years, while the terminology young people covers the age of 10 to 24 years (1).

The total number of world population in the mid of 2007 is estimated to be more than 6.6 billion, out of which about 1.4 billion are adolescents, which means adolescents make up of one-fifth of the world's population (2).
Adolescent is a transition period in life from dependent childhood to self-reliant adulthood and includes the range in which the majority of young people join the labour force. It is the period where young person achieve the highest stage of cognitive and physical development and strive to define their self-identity. A need for independence is also one of the features of this group (3).

Adolescents life are at risk because they do not have the information, skills, health services and support they need to go through sexual development during adolescent (4).

The vast majority of sexual intercourse during 
adolescence/youth period is unprotected. Therefore, risk of unwanted pregnancy, unsafe abortion, and STIs/HIV/AIDS is very high. In addition, lack of accurate information about reproductive health and sexuality, lack of access to health services, lack awareness about contraception and vulnerability to sexual abuse put youth at highest risk (5).

According to WHO, 333 million new cases of STIs occur worldwide each year, and at least 111 million of these cases occur in people under age 25 years. In developing countries, nearly half of all HIV infections occur in men and women younger than 25 years this data indicate that up to $60 \%$ of all new HIV infections are among 15 to 24 years (6).

Young people are at high risk of STIs/HIV for a variety of reasons, such as lack of knowledge about STIs/HIV, not perceiving themselves to be at risk, lack of access to or inconsistent use of condoms, increased number of sexual partners leading to increased risk of exposure, biological factors (a young woman's cervical epithelium is more susceptible to infections), economic factors (adolescents may live or work on the street and participate in "survival sex" or "transactional sex") and social factors: being forced into a sexual relationship, lacking the skills and power to negotiate condom use, and encountering gender norms, double standards, cultural, religious regarding sexuality and fertility (6).

Socioeconomic status, joblessness, sexually active friends, family instability, single-parent household, sibling sexual activity and individual characteristics (race, gender, age, and pubertal status) have all been associated with adolescent sexual outcomes (7).

Ethiopia is one of the developing African countries where HIV/AIDS is fuelling and striking its population of all age including adolescents. Elsewhere in Africa, transmission of HIV/AIDS is almost exclusively through heterosexual contact and about $1.4 \%$ of adult age 15-49 were living with HIV in 2005 (8). Among women age 15-19 years 0.7\% are HIV infected, compared with $0.1 \%$ of men age $15-19$ years. HIV prevalence among women $20-24$ is $1.7 \%$ that is three times more than men in the same age group which account $0.4 \%$ (8).

Sexual initiation among youth is associated with divorced parents, less education, low income, dropping out of school, permissive attitudes, and lack of confidence to avoid sex, peer pressure, drinking, drug use, previous sexual abuse and exposure to sexual content of media (9).

Misconceptions about HIV/AIDS are wide spread among young people. They vary from one culture to another and particular norm gain currency in some populations both on how HIV is spread and how to prevent. Surveys from 40 countries indicate that more than $50 \%$ of young people aged 15 to 24 years had serious misconceptions about how HIV/AIDS is transmitted. Stigma and discrimination discourage young peoples from taking preventive measures against HIV/AIDS, like using condoms, seeking treatment for infections, voluntary counselling and testing and informing their sexual partner (10). Along with increased exposure to STIs and unintended pregnancy youth who engage in sexual activity outside of marriage may face social stigmas, family conflicts, problems with school and the potential need for unsafe abortions (11).

Effective prevention that enables people to adopt safer behaviour requires not only just knowing who is at risk, but also understanding why they engage in risk behaviours, motivating them to reduce their risk, developing their knowledge and skills, improving their access to means of prevention in ways that are appropriate to them and providing a supportive social and policy environment for behavioral change. Youth must learn the facts before they become sexually active and the information needs to be regularly reinforced and built on both in the classroom and beyond (12).

A basic education of good quality for all children offering sound knowledge about sexuality and HIV is essential. Any intervention measure towards youth should appropriately aim at school which is where at least a substantial proportion of them are found. School is easy and conducive to provide them with information alongside their formal training and most important of all they will have the chance to internalize what they have been taught among themselves. Although very few studies have assessed youth risky sexual behaviour and associated factors and most of these studies are conducted in major towns.

Therefore, the aim of this study was to assess risky sexual behaviour and associated factors among youth in the study area.

\section{Methods and Materials}

The study was conducted in Pawe Woreda, Metekel Zone Benishangul Gumuz Regional state, which is located $573 \mathrm{kms}$ from Addis Ababa and $400 \mathrm{kms}$ away from Assosa (main town of the region). It is located in the Northwest part of the Ethiopia, has 20 Kebeles, and its boundary: Dangur woreda in the west, Mandura woreda in the south and Awi zone in Amhara regional state from the north. According to 2007 census population of the woreda is 37,711 (when it projected to $2011 / 12)$ is that 41,949 population $(21,348$ were males and 20,601 were females). The woreda has 3 high schools, 34 primary schools, 16 health posts, 3 health centers, 11 private drug vendors, 5 private clinics, 1 General hospital and one Health Sciences College. Based on education profile of Pawe Woreda, in 2011/12 academic year, a total of 2,926 (1,522 males and 1,404 females) students were enrolled in secondary schools in grades 9-12. The study was carried out from May $10^{\text {th }}$ to $20^{\text {th }}, 2012$ in Pawe Woreda.

School based cross-sectional study design was employed both quantitative and qualitative data collection methods. Source population was all high school students who were enrolled in grade $9^{\text {th }}-12^{\text {th }}$ in $2011 / 2012$ in the Pawe Woreda. Whereas, study population were all students aged 15 to 24 years attending their education during the study period and who were selected from three high schools. For qualitative study, students 15-24 years of age who were anti AIDs club members, members of student council and those who were not involved in quantitative part were involved. However, exclusion criteria for the study were those students who were critically medically ill and mentally disabled students. 
The sample size was calculated using the single population proportion formula. The value of $\mathrm{p}$ was taken as $50 \%$ as there is no previous study done in the study area and nearby.

$$
\mathrm{n}=\frac{(Z \alpha / 2)^{2} \mathrm{p}(1-\mathrm{p})}{\mathrm{d}^{2}}
$$

$\mathrm{Z}=$ the standard normal deviation at $95 \%$ confidence level $=1.96$

$\mathrm{P}=50 \%$ the proportion of study population with expected prevalence of risky sexual behaviour

$\mathrm{d}=$ the desired precision (marginal error) $5 \%$

$\mathrm{n}_{\mathrm{i}}=$ initial sample size

$\mathrm{n}_{\mathrm{f}}=$ final sample size

$\mathrm{N}=$ total population of school youth $=2926$

$$
\mathrm{n}_{\mathrm{i}}=\frac{(1.96)^{2} 0.5(1-0.5)}{(0.05)^{2}}=384
$$

Finite population correction formula was used since the total population is less than 10,000 .

$$
\begin{gathered}
\mathrm{n}_{\mathrm{f}}=\frac{\mathrm{n}_{\mathrm{i}}}{1+\frac{\mathrm{n}_{\mathrm{i}}}{\mathrm{N}}}=\frac{384}{1+\frac{384}{2926}}=340+10 \% \text { non-response } \\
\mathrm{n}_{\mathrm{f}}=340+10 \% \text { non-response }=\underline{374}
\end{gathered}
$$

For the qualitative study, two groups consisting of 6 students of both sex from each school were included making a total of six FGDs.

Sampling technique was used multistage sampling technique. At the beginning three high schools were selected by simple sampling technique. Secondly, 374 students were selected by simple random sampling from each section in the selected high school.

Dependent variable of the study was risky sexual behavior of youth. However, independent variables: Sociodemographic variables such as sex, age, grade, mother's occupation, marital status, father's educational level, mother's educational level, father's occupation and peer pressure. In addition, knowledge of STI/HIV, pocket money, alcohol use, khat chewing, cigarette smoking and self-risk perception were independent variables.

Data collection process; six data collectors who were grade 10 completed students were recruited. The data collectors and the supervisors were given training for 3 days. The principal investigator moderated the discussion for the male groups, while female groups were moderated by female nurse who was trained by the principal investigator for an average of forty minutes. Supervisors supervised and support data collectors during the data collection process. For quantitative part; Structured and semi structured pre- coded questionnaires that are adopted from previous similar studies conducted in South-Gondar in 2004 and Aleta Wondo in 2008 made a suitable for this particular study was used.

Pre-test the questionnaire for clarity and consistencies of the questions were done on 19(5\%) of the total samples at the Manbuk high school in Dandur Woreda which is outside of the study area one week prior to the actual data collection. The questionnaire was initially prepared in English and then translated in to Amharic. The Amharic version was again translated back to English to check for any inconsistencies.

After data collection; data was code, entered, cleaned and analyzed using SPSS version 16. Descriptive statistics was calculated to describe the overall distribution of the study subject with the variables under study. Bivariate and multivariable logistic regression analyses were used to determine the presence of statistically significant associations between the dependent and the independent variables. For qualitative part; to support the quantitative study, Focus Group Discussion was conducted using a discussion guide. Discussion was supported with tape-recorded and the facilitators have taken notes. Data from the FGDs were organized into thematic areas, coded and presented in narratives in triangulation with the quantitative results.

Ethical clearance was obtained from the ethical review committee of Jimma University. Official permission was secured from different authorities of the Pawe Woreda. The respondents were informed about the objective and purpose of the study then after verbal and written consent was obtained from each respondent.

\section{Results}

\begin{tabular}{|c|c|c|c|}
\hline Variables $(n=374)$ & Male n (\%) & Female n (\%) & Total n (\%) \\
\hline \multicolumn{4}{|l|}{ Age: } \\
\hline $15-17$ & $95(25.4 \%)$ & $120(32.1 \%)$ & $215(57.5 \%)$ \\
\hline $18-24$ & $100(26.7 \%)$ & $59(15.8 \%)$ & $159(42.5 \%)$ \\
\hline \multicolumn{4}{|l|}{ Grade: } \\
\hline $9^{\text {th }}$ & $82(21.9 \%)$ & $108(28.9 \%)$ & $190(50.8 \%)$ \\
\hline $10^{\text {th }}$ & $69(18.4 \%)$ & $37(9.9 \%)$ & $106(28.3 \%)$ \\
\hline $11^{\text {th }}$ & $205.3 \%)$ & $21(5.6 \%)$ & $41(11.0 \%)$ \\
\hline $12^{\text {th }}$ & $24(6.4 \%)$ & $13(3.5 \%)$ & $37(9.9 \%)$ \\
\hline \multicolumn{4}{|l|}{ Marital status: } \\
\hline Married & $5(1.3 \%)$ & $17(4.5 \%)$ & $22(5.9 \%)$ \\
\hline Unmarried & $190(50.8 \%)$ & $160(42.8 \%)$ & $350(93.6 \%)$ \\
\hline \multicolumn{4}{|l|}{ Ethnicity: } \\
\hline Amhara & $140(37.4 \%)$ & $142(38.0 \%)$ & $282(75.4 \%)$ \\
\hline Kambata & $10(2.7 \%)$ & $9(2.4 \%)$ & $19(5.1 \%)$ \\
\hline Agew & $21(5.6 \%)$ & $17(4.5 \%)$ & $38(10.2 \%)$ \\
\hline Others & $24(6.4 \%)$ & $11(2.9 \%)$ & $35(9.3 \%)$ \\
\hline \multicolumn{4}{|l|}{ Religion } \\
\hline Orthodox & $145(38.8 \%)$ & $129(34.5 \%)$ & $274(73.3 \%)$ \\
\hline Protestant & $20(5.3 \%)$ & $10(2.7 \%)$ & $30(8.0 \%)$ \\
\hline Catholic & $4(1.1 \%)$ & $2(0.5 \%)$ & $6(1.6 \%)$ \\
\hline Muslim & $26(7.0 \%)$ & $38(10.2 \%)$ & $64(17.1 \%)$ \\
\hline \multicolumn{4}{|l|}{ Living With } \\
\hline Father and Mother & $117(31.3 \%)$ & $114(30.5 \%)$ & $231(61.8 \%)$ \\
\hline Mother Only & $34(9.1 \%)$ & $22(5.9 \%)$ & $56(15.0 \%)$ \\
\hline Father Only & $7(1.9 \%)$ & $7(1.9 \%)$ & $14(3.7 \%)$ \\
\hline Relatives & $11(2.9 \%)$ & $21(5.6 \%)$ & $32(8.6 \%)$ \\
\hline Alone & $5(1.3 \%)$ & $8(2.1 \%)$ & $13(3.5 \%)$ \\
\hline Friends & $14(3.7 \%)$ & $2(0.5 \%)$ & $16(4.3 \%)$ \\
\hline Others & $7(1.9 \%)$ & $5(1.3 \%)$ & $12(3.2 \%)$ \\
\hline \multicolumn{4}{|l|}{ Pocket Money } \\
\hline Yes & $44(11.8 \%)$ & $34(9.1 \%)$ & $78(20.9 \%)$ \\
\hline No & $151(40.4 \%)$ & $145(38.8 \%)$ & $296(79.1 \%)$ \\
\hline
\end{tabular}

\subsection{Socio - Demographic Characteristics}

Table 1. Socio-Demographic characteristics of high school youth, Pawe woreda, Metekel Zone, Benishangul Gumuz Region, May 2012. 
A total of 374 youth participated in the study. Out of them $51.9 \%$ were males. The mean age of the study population was $17.32 \pm 1.59$ SD years. Majority of the respondents $(80.2 \%)$ were in $15-18$ years of age. Three hundred forty nine $(93.6 \%)$ of the participants were never married. One hundred ninety $(50.8 \%)$ of the respondents were grade $9^{\text {th }}, 106(28.3 \%)$ were grade $10^{\text {th }}$ and the remaining were grade $11^{\text {th }}$ and $12^{\text {th }}$. The majority of respondents; 281 (75.1\%) were Amhara by ethnic group and $273(73 \%)$ were orthodox Christian followed by Muslim, 64(17.1\%). Two hundred twenty eight (61\%) were living with their parents while $13(3.5 \%)$ were living alone (Table 1).

\subsection{Sexual Behavior}

\subsubsection{Sexual History}

Overall, $90(24.1 \%)$ of the respondents $\{55(61.1 \%)$ were males and $35(38.9 \%)$ were females $\}$ were reported that they had practiced sexual intercourse. Among the study participants who had practice sexual intercourse, 76(84.4\%) were below the age of 18years and the mean age at first sexual intercourse was $14.61 \pm 2.89 \mathrm{SD}$ for male and 15.74 +2.165 SD years for female (Table-2).

\subsubsection{Risky Sexual Behavior}

Among 90(24.1\%) students who ever had sexual intercourse, 37(41.1\%) had used condoms during the first time when they had sexual intercourse while 53(58.9\%) were never used. Out of those $37(41.1 \%)$ students who were sexually active and ever used condom during the previous 12 months, $12(32.4 \%), 9(24.3 \%)$ and $16(43.2 \%)$ of students were using condoms sometimes, most of the time and always respectively.

The reason for none or inconsistent use of condoms were trust partner 21(39.6\%), don't like 13(24.5\%), don't think of it $4(7.5 \%)$, too expensive $4(7.5 \%)$ and used other contraceptive $3(5.7 \%)$, religious prohibition $3(5.7 \%)$, partner objection $3(5.7 \%)$ and others $2(3.8 \%)$. Among sexually active male respondents; only $3(5.5 \%)$ of them had history of sexual intercourse with female commercial sex workers. Although $48(64.9 \%)$ of the respondents in this study had one sexual partner in the past, still significant proportion $26(35.1 \%)$ reported to have two or more sexual partners. Of the study participants $74(19.8 \%)$ and out of sexually active students $74(82.2 \%)$ have developed risky sexual behavior. This finding was supported by the FGDs where the discussants emphasized the idea that peer pressures, experimentation by the youth and intensive sexual urge were the major reasons mentioned for multiple sexual partners

The reasons reported for the initiation of the first sexual intercourse encounter in those who ever practiced sexual intercourse were in $26(28.9 \%)$ of them sexual desire, in $22(24.4 \%)$ marriage, in $18(20 \%)$ of them love and $18(20 \%)$ of the respondents peer pressure, $(4.4 \%)$ rape, $1(1.1 \%)$ get drunk and the remaining $1(1.1 \%)$ others (Figure 1$)$.
Table 2. Sexual behavior of high school youth, in Pawe Woreda, May 2012.

\begin{tabular}{|c|c|c|}
\hline Variables & Number & Percent \\
\hline \multicolumn{3}{|c|}{ Ever had sexual intercourse: $n=374$} \\
\hline Yes & 90 & 24.1 \\
\hline No & 284 & 75.9 \\
\hline \multicolumn{3}{|c|}{ Sex: of sexually active $n=90$} \\
\hline Male & 55 & 61.1 \\
\hline Female & 35 & 38.9 \\
\hline \multicolumn{3}{|l|}{ Age at first sex: $n=90$} \\
\hline$<15$ & 48 & 53.3 \\
\hline $15-17$ & 28 & 31.1 \\
\hline$>=18$ & 14 & 15.6 \\
\hline \multicolumn{3}{|c|}{ Number of sexual partner: $n=90$} \\
\hline One & 49 & 54.4 \\
\hline Two and more & 41 & 45.6 \\
\hline \multicolumn{3}{|l|}{ Ever condom use $\mathrm{n}=90$} \\
\hline Yes & 37 & 41.1 \\
\hline No & 53 & 58.9 \\
\hline \multicolumn{3}{|c|}{$\begin{array}{l}\text { Frequency of condom use during any sexual } \\
\text { episode: } n=90\end{array}$} \\
\hline Some times & 12 & 32.4 \\
\hline Most of the time & 9 & 24.3 \\
\hline Always & 16 & 43.2 \\
\hline \multicolumn{3}{|c|}{ Reason For not/Inconsistent Condom Use } \\
\hline Too expensive & 4 & 7.5 \\
\hline Partner objection & 3 & 5.7 \\
\hline Used other contraceptive & 3 & 5.7 \\
\hline Don't like & 13 & 24.5 \\
\hline Trust partner & 21 & 39.6 \\
\hline Don't think of it & 4 & 7.5 \\
\hline Religious prohibition & 3 & 5.7 \\
\hline Others & 2 & 3.8 \\
\hline \multicolumn{3}{|c|}{ Sexual intercourse with CSW : $\mathrm{n}=53$} \\
\hline Yes & 3 & 5.5 \\
\hline No & 52 & 94.5 \\
\hline \multicolumn{3}{|c|}{ Condom use with commercial partner/CSW } \\
\hline Yes & 2 & 66.7 \\
\hline No & 1 & 33.3 \\
\hline \multicolumn{3}{|c|}{ Risky sexual behavior: $n=374$} \\
\hline Yes & 74 & 19.8 \\
\hline No & 300 & 80.2 \\
\hline
\end{tabular}

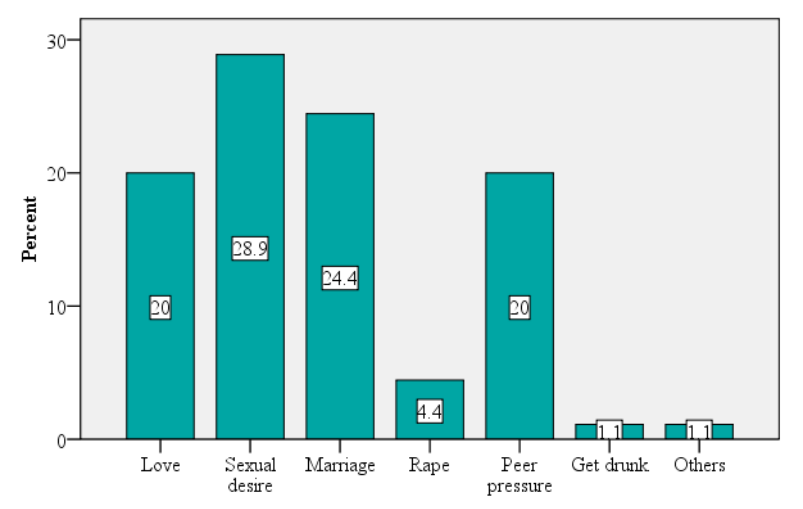

Figure 1. Factors initiated sex for the first time among high school youth, Pawe woreda, Metekel zone, Benishangul Gumuz Region, May 2012. 


\subsection{Risk Perception}

Table 3. School adolescents risk perception among high school youth in pawe woreda, May 2012.

\begin{tabular}{|c|c|c|c|}
\hline Variables & Male n(\%) & $\begin{array}{l}\text { Female n } \\
(\%)\end{array}$ & Total n (\%) \\
\hline \multicolumn{4}{|l|}{$\begin{array}{l}\text { Chance of acquiring } \\
\text { HIV/STI }\end{array}$} \\
\hline No chance & $18(64.3 \%)$ & $10(35.7 \%)$ & $28(31.1 \%)$ \\
\hline Low chance & $15(53.6 \%)$ & $13(46.4 \%)$ & $28(31.1 \%)$ \\
\hline High chance & $15(62.5 \%)$ & $9(37.5 \%)$ & $24(26.7 \%)$ \\
\hline Don't know & $7(70 \%)$ & $3(30 \%)$ & $10(11.1 \%)$ \\
\hline Total & $55(61.1 \%)$ & $35(38.9 \%)$ & $90(100.0 \%)$ \\
\hline \multicolumn{4}{|l|}{ Why at risk: } \\
\hline Having multiple partner & $7(29.2 \%)$ & $1(4.2 \%)$ & $8(33.3 \%)$ \\
\hline Never use condom & $3(12.5 \%)$ & $4(16.7 \%)$ & $7(29.2 \%)$ \\
\hline $\begin{array}{l}\text { Inconsistently use condom } \\
\text { Why not at risk: }\end{array}$ & $5(20.8 \%)$ & $4(16.7 \%)$ & $9(37.5 \%)$ \\
\hline Abstain from intercourse & $11(19.6 \%)$ & $7(12.5 \%)$ & $18(32.1 \%)$ \\
\hline Faithful to my partner & $18(32.1 \%)$ & $14(25 \%)$ & $32(57.1 \%)$ \\
\hline Use always condom & $3(5.4 \%)$ & $1(1.8 \%)$ & $4(7.1 \%)$ \\
\hline
\end{tabular}

Among students who ever had sex, regards to personal perception to HIV/STI, $24(26.7 \%)$ of the students $\{15(62.5 \%)$ males and $9(37.5 \%)$ females $\}$ claimed that their chance of contracting HIV/STI was high. Whereas $28(31.1 \%)$ of students [18(64.3\%) males and 10(35.7\%) females] reported there was no chance at all. Reasons given by the students for being at high risk was, $9(37.5 \%)$ did not use condoms consistently, $8(33.3 \%)$ had more than one sexual partner and 7 (29.2\%) never used condom (Tables 3 ).

FGD result also showed that substance use like alcohol, khat and cigarette smoking were among the factors that pushed school adolescents to sexual initiation in an early age and reasons why youth do not perceive themselves at risk of HIV/STI are due to over pleasure in alcohol and khat which make them not to think of risk.

\subsection{Factors Related to Risky Sexual Behavior}

To examine the effect of some of the explanatory variables by controlling the effect of confounders on risky sexual behavior exposing them to HIV/STI, regression analysis was carried out. Age group 18-24 years AOR=3.279 (95\% CI: $1.79,6.008)$ and alcohol consumption $\mathrm{AOR}=9.1$ (95\% CI: $2.517,32.9)$ were independently and positively associated with risky sexual behavior. Other variables did not show any statistically significant (Tables 4).

Table 4. Selected Socio-demographic predictors of risky sexual behavior among high school youth Pawe Woreda, Metekel Zone, May 2012.

\begin{tabular}{|c|c|c|c|c|}
\hline \multirow{2}{*}{ Variables } & \multicolumn{4}{|c|}{ Risky Behavior } \\
\hline & Yes n (\%) & No n (\%) & Crude OR(95\% CI) & Adjusted OR(95\% CI) \\
\hline \multicolumn{5}{|l|}{ Age: } \\
\hline $15-17$ & $28(13 \%)$ & $187(87 \%)$ & 1.00 & 1.00 \\
\hline $18-24$ & $46(28.9 \%)$ & $113(71.1 \%)$ & $2.719(1.609,4.594)^{*}$ & $3.279(1.79-6.008)^{*}$ \\
\hline \multicolumn{5}{|l|}{ Sex: } \\
\hline Female & $28(15.6 \%)$ & $151(84.4 \%)$ & 1.00 & 1.00 \\
\hline Male & $46(23.6 \%)$ & $149(76.4 \%)$ & $1.665(0.988-2.805)$ & $0.71(0.402-1.253)$ \\
\hline \multicolumn{5}{|l|}{ Grades } \\
\hline $9-10$ & $57(19.3 \%)$ & $239(80.7 \%)$ & $0.856(0.465-2.570)$ & $0.755(0.371-1.545)$ \\
\hline $11-12$ & $17(21.8 \%)$ & $61(78.2 \%)$ & 1.00 & 1.00 \\
\hline \multicolumn{5}{|l|}{ Marital status } \\
\hline Married & $4(18.2 \%)$ & $18(81.8 \%)$ & 1.00 & 1.00 \\
\hline Not married & $69(19.7 \%)$ & 281(80.3\%) & $1.105(0.362-3.37)$ & $1.069(0.336-3.403)$ \\
\hline Widowed/divorced & $1(50 \%)$ & $1(50 \%)$ & $4.5(0.229-88.243)$ & $03.589(0.143-90.034)$ \\
\hline \multicolumn{5}{|l|}{ Fathers Education Level } \\
\hline Illiterate & $22(21 \%)$ & $83(79 \%)$ & $0.962(0.548-1.69)$ & $1.07(0.49-2.336)$ \\
\hline Literate & $50(20.3 \%)$ & $196(79.7 \%)$ & 1.00 & 1.00 \\
\hline \multicolumn{5}{|l|}{ Mother Education Level } \\
\hline Illiterate & $23(16.8 \%)$ & $114(83.2 \%)$ & $0.248(0.417-1.254)$ & $0.57(0.269-1.209)$ \\
\hline Literate & $48(21.8 \%)$ & $172(78.2 \%)$ & 1.00 & 1.00 \\
\hline \multicolumn{5}{|l|}{ Fathers Occupation } \\
\hline Unemployed & $52(20.6 \%)$ & $200(79.4 \%)$ & $1.095(0.609-1.967)$ & $1.42(0.697-2.894)$ \\
\hline Employed & $19(19.2 \%)$ & $80(80.8 \%)$ & 1.00 & 1.00 \\
\hline \multicolumn{5}{|l|}{ Mother's Occupation } \\
\hline Unemployed & $53(18.7 \%)$ & $231(81.3 \%)$ & $0.701(0.381-1.291)$ & $0.599(0.286-1.254)$ \\
\hline Employed & $18(24.7 \%)$ & $55(75.3 \%)$ & 1.00 & 1.00 \\
\hline \multicolumn{5}{|l|}{ Living With } \\
\hline With at least one parent & $52(17.3 \%)$ & 249 (82.7\%) & 1.00 & 1.00 \\
\hline Not living with the parent & $22(30.1 \%)$ & $51(69.9 \%)$ & $2.066(1.154,3.698)$ & $2.922(.44719 .107)$ \\
\hline \multicolumn{5}{|l|}{ Pocket Money } \\
\hline Yes & $17(21.8 \%)$ & $61(78.2 \%)$ & $1.169(0.635-2.151)$ & $1.305(0.673-2.531)$ \\
\hline No & $57(19.3 \%)$ & $239(80.7 \%)$ & 1.00 & 1.00 \\
\hline \multicolumn{5}{|c|}{ Knowledge on mode of HIV transmission: } \\
\hline No & $25(20.2 \%)$ & $99(79.8 \%)$ & $0.779(0.465-1.306)$ & $1.358(0.264-6.978)$ \\
\hline Yes & $49(19.6 \%)$ & 201(80.4\%) & 1.00 & 1.00 \\
\hline \multicolumn{5}{|c|}{ Knowledge on HIV prevention: } \\
\hline No & $30(17.6 \%)$ & $140(82.4 \%)$ & $1.036(0.605-1.775)$ & $0.548(0.12-2.50)$ \\
\hline Yes & $44(21.6 \%)$ & $160(78.4 \%)$ & 1.00 & 1.00 \\
\hline
\end{tabular}




\begin{tabular}{lllll}
\hline Variables & \multicolumn{2}{l}{ Risky Behavior } & & \\
\cline { 2 - 5 } & Yes n (\%) & No n (\%) & Crude OR(95\% CI) & Adjusted OR(95\% CI) \\
\hline Self risk perception: & $55(83.3 \%)$ & $11(16.7 \%)$ & 1.00 & 1.00 \\
No/low chance/ Don't know & $19(79.2 \%)$ & $5(20.8 \%)$ & $1.316(0.405-4.277)$ & $1.706(0.441-6.595)$ \\
High chance & $19(8.2 \%)$ & $213(91.8 \%)$ & 1.00 & 1.00 \\
Alcohol consumption: & $55(38.7 \%)$ & $87(61.3 \%)$ & $7.087(3.976-12.634)^{*}$ & $9.1(2.517-32.9)^{*}$ \\
Never Drunk & & & & 1.00 \\
Drunk & $62(18.2 \%)$ & $278(81.8 \%)$ & 1.00 & $0.42(0.091-1.942)$ \\
Khat chewing: & $12(35.3 \%)$ & $(64.7 \%)$ & $2.446(1.149-5.205)^{*}$ & 1.00 \\
Never chewed & & & & $0.392(0.053-2.873)$ \\
Chewed & $72(19.5 \%)$ & $297(80.5 \%)$ & 1.00 & $2.75(0.451-16.764)$ \\
Cigarette Smoking: & $2(40.0 \%)$ & $3(60.0 \%)$ & & \\
Never Smoked & & & & \\
Smoked & & & & \\
\hline
\end{tabular}

\section{Discussion}

This study attempted to assess the risky sexual behavior of youth, their risk perception to HIV/STI and factors that expose them to risky behaviors among high school youth. In this study $90(24.1 \%)$ of the respondents reported that they had practiced sexual intercourse.

The mean age at first sexual intercourse was $14.61 \pm 2.89$ SD for male and $15.74 \pm 2.165$ SD years for female. The study done among high school youth in Bullen woreda, showed similar finding in that the mean age of sexual commencement was $16.1 \pm 2.1 \mathrm{SD}$ (13). Study conducted in Aleta Wondo Town, 37.6\% of the participating youths admitted to ever have sexual experience during their life time (14). The study done among high school students in Bahir Dar Town in the northern part of Ethiopia showed similar finding in that the mean age of sexual commencement was $15.5 \pm 2.3(15)$.

Male students were found to start sexual intercourse earlier than female and were found to be more exposed to risky sexual behavior than female students 46(62.2\%) males initiate sex early compared to $28(37.8 \%)$ females. This might suggest that adolescents/youth begin sex too early, which could as a result expose them to develop risky sexual behavior and its consequences. The finding one can understand youth were started to practice sexual intercourse in the early age of their life, which point out the need to give an attention in building life skill for adolescents/youth.

In this study the reasons reported by the students for the initiation of sexual intercourse in those who ever practiced sexual intercourse were sexual desire $(27 \%)$, marriage $(25.7 \%)$, love $(24.3 \%)$ and peer pressure(16.2\%). Similarly, a study conducted in Bale, Oromia region found that personal desire (39.1\%) and peer pressure 60 (23.3\%) (16). In other study done in Aleta wondo town among school youth reported the reasons for the initiation of sexual activity were to prove love of boy/girlfriend $29.4 \%$ and peer pressure $23.5 \%$ (14). In addition, the qualitative findings showed that the main factors that push school youth or adolescents to engage in an early sexual intercourse, as agreed by both male and female group are early marriage, peer pressure, substance use (like alcohol, khat and cigarette) and illegal video house/ watching pornography film.

Although $48(64.9 \%)$ of the respondents in this study had one sexual partner in the last 12 months, still significant proportion $26(35.1 \%)$ reported to have two or more sexual partners. A study conducted in west Gojam zone on school youth, $33.3 \%$ reported having had two or more sexual partners (17). This finding is lower than study conducted in Bale Zone and in Mojo Town which showed that $47.7 \%$ and $53.1 \%$ of students reported to have sexual intercourse with more than one partner respectively $(16,18)$. This discrepancy might be due to the difference in the growth of the town, since changing conditions due to urbanization and life style, put the health of adolescents at risk. Among sexually active respondents, about 3(5.5\%) male students reported experiencing commercial sex, which is lower than similar previous studies. In other study done among high school adolescents in Bale Zone, higher proportion (20.5\%) of males had sexual intercourse with commercial sex workers (16). On the other hand $14.8 \%$ of high school adolescents in South Gondar Zone had sex with commercial sex workers (19). In a study done in Mojo revealed 38\% adolescent male have reported exercising sex with CSWs (19). The lower result in this study could be due to increased awareness of students about HIV/AIDS or it could be due to under reporting.

Another feature that makes sexual activity of youth at high risk to HIV/STI is none or inconsistent use of condom. In this study, of 90 sexually active students 53(58.9\%) of high school youth have never used condoms during any sexual episode, 37(41.1\%) reported ever used condom and only $16(43.2 \%)$ of them claim to have used condoms consistently in the last 12 months. The study done in Aleta Wondo Town among school youth reported majority of school youth $64.1 \%$ have never used condoms during any sexual episode, $35.9 \%$ reported ever used condom and only $23.9 \%$ of them claim to have used condoms consistently(14). The finding of this study is almost similar to a study, which was $48 \%$ among high school youth in Dessie, 58.1\% among school adolescents in Bale of Oromia region and $41.7 \%$ among adolescents in South Gondar of Amhara Region (15, 16, 19). This finding is also consistent with the FGD conducted in this study, which indicates that reasons for none-use of condom are perceived reduction in sexual pleasure, shame to buy, trusting partners and opposition by partner. Low consistent utilization of condom in this study is an indication of the fact that high-risk behaviors are still widely practiced among high school youth. 
This might indicate that the risk taking behavior among school youth is high which needs emphasis in changing their sexual behavior. This calls for well-organized information, education and communication to bring behavioral change. In this study reasons mentioned not to use condom were trust partner $19(37.3 \%)$, don't like $11(21.6 \%)$, don't think of it $5(9.8 \%)$, used other contraceptive $4(7.8 \%)$, religious prohibition $3(5.9 \%)$ and others $9(17.7 \%)$. Similar study conducted in Aleta Wondo Town revealed that the barrier or reasons not to using condoms among school youths were lack of information $28.7 \%$, decrease sexual pleasure $26.1 \%$, peer/ partner influence $18.3 \%$, fear or embracement to buy and condoms unavailable nearby were account $15.7 \%$ each (14).

According to study conducted in Mojo, among respondents who started sexual intercourse and experienced peer pressure, $43.4 \%$ of them have multiple sexual partners and $80 \%$ of them not used condom consistently in the last 12 months (18). In this study $74(19.8 \%)$ of the study participants have developed risky sexual behavior.

In this study, majority of the respondents, knew that HIV is transmitted through unprotected sexual intercourse 344(92\%), infected blood 278 (74.3\%), contaminated sharps 233(62.3\%) and respondents stated mother to child transmission 195(52.1\%). A similar study conducted in Bale revealed that the knowledge on mode of HIV transmission known by the school youth were, unsafe sex $94.3 \%$, unsafe injection $54.7 \%$, contaminated blood transmission $45.7 \%$, and mother-to-child transmission $37.8 \%$ (16).

Two hundred ninety five $(78.9 \%), \quad 272(72.7 \%)$, $230(61.5 \%), 121(32.4 \%)$, and $113(30.2 \%)$ of school youth mentioned faithful to one sex partner, abstaining, using condom, avoiding contaminated sharp objects, and avoiding unsafe injection as a means of preventing HIV/AIDS and STD, respectively. Almost all the FG-discussants mentioned about HIV/AIDS/STIs with its transmission and prevention methods. A similar study conducted in Bale revealed that preventive measure $75.3 \%$ abstinence, faithful to one partner $58.4 \%$, and condom use $53.3 \%$ (16).

This study found that personal perception to HIV/STI 24 $(26.7 \%)$ of the students claimed that their chance of contracting HIV/AIDS/STI was high while $28(31.1 \%)$ said there was no chance at all. Twenty eight 28 (31.1\%) low chance and $10(11.1 \%)$ did not know their risk status. Study found that only $24.5 \%$ of students perceived that they were at risk to HIV infection, $12.7 \%$ did not know whether they are at risk or not and $62.9 \%$ they are perceived not at risk. The study conducted on high-risk sexual behavior among youth in Tanzania revealed that $11.7 \%$ of the participants felt that they were at a high risk of getting HIV/AIDS and STDS, 25\% felt that they had a very low risk, while $53.1 \%$ felt that they were not at risk at all (20). Other study done in Gondar showed $5.42 \%$ of the students claimed that their chance of contracting HIV/AIDS was high while $25.20 \%$ said there was no chance at all. One hundred and $28.73 \%$ did not know their risk status (19). Other study done in Asella Teaching Hospital reveals $206(82.1 \%)$ believed as they were at a risk of acquiring HIV infection and 127(50.6\%) respondents leveled themselves as high risk to HIV infection. From the total participants $64(25.5 \%)$ experienced needle stick or other sharp injuries, among them 45 (17.9\%) experienced injury only one time and $16(6.4 \%)$ had encountered more than two times within their life time (21).

Some of the reasons why they are at risk: $55 \%$ had sex without condom, $25 \%$ had multiple sexual partners, $19.2 \%$ had sex with female commercial sex workers and $18.3 \%$ had unsafe injections (14). Low level of risk perception in this study might suggest school youth do not sense the consequence of risky sexual behavior which needs intensive intervention in developing life skills of youth. This study revealed substance use $38.7 \%$ had used alcohol, $35.3 \%$ of them had used "khat" and only 2(40\%) smoked cigarette. Study conducted among school youth in Bale reported substance used by study subjects $20.1 \%$ of them have used alcohol, $17.3 \%$ khat, $5.7 \%$ cigarette and $3.6 \%$ cannabis (16). In another study among school youth in west Gojam showed nine $(2.9 \%)$ and two hundred twenty one $(73.6 \%)$ students reported consumption of khat and alcohol respectively (17). Study done at St. Marry University Students in Ethiopia, the life style of the study subjects were indicate that the prevalence was high $16(8.6 \%), 13(11.2 \%), 7(24.1 \%)$, and $26(7.9 \%)$ respectively among alcohol drinkers, chat chewers, cigarette smokers and pornographic movie watchers as compared to their counterparts (22).

This study showed that the odds of having risky sexual behavior were nine times higher for those who drank alcohol at least once than who never drunk with $(\mathrm{AOR}=9.1(95 \% \mathrm{CI}$ : $2.517,32.9)$. This increased rate of alcohol use in the town may indicate that the availability of places for adolescents to spend time out of school there by involve themselves to risky sexual behavior.

Age group of 18 to 24 years were three times more likely to practice risky sexual behavior than those in the age group of 15 to 17 years old ( $\mathrm{AOR}=3.279$ (95\% CI:1.79, 6.008). This may be attributed to high peer pressure and influence of not being living with family and increase their sexual desire age the increase in the youth age group.

\section{Conclusions and Recommendation}

Based on the finding majority of students were sexually active before the age eighteen and majority of sexually active had risky sexual behaviour. Also the study indicated unprotected sex, multiple sexual partners and sex with female commercial sex workers as risky sexual behaviour. Alcohol consumption and older age were important predictors of risky sexual behaviour. There is low HIV/STIs self-risk perception among school youths.

Therefore, this study recommendations that the school administration and school teachers should take the initiative to bring about healthy sexual behaviour among their students by strengthening anti-AIDS and reproductive health clubs in the schools. In addition to the above recommendation increasing trend in alcohol use by school adolescents/youth which influences them to practice risky sexual behaviours 
and the environmental factors facilitating these behaviours need immediate attention by the school and other concerned government bodies.

\section{Limitations of the Study}

This study is subject to several limitations. The behavioral outcomes are based on self-reported information, which is subject to reporting errors and bias. Since the study is on very sensitive and private issues the possibility of underestimation cannot be ruled out. As the study focuses on high school youth and although school enrolment rate is high, the results may not represent out of school youth.

Finally, this study was based on cross-sectional data, which implies that the direction of casual relationships cannot always be determined.

\section{Abbreviation}
AOR: Adjusted Odd Ratio
HIV: Human Immuno Virus
STI: Sexual Transmitted Infectious
STDs: Sexual Transmitted Diseases
FGD: Focus Group Discussion
IEC: Information Education Communication
BCC: Behavioral Chang Communication
WHO: World Health Organization
SD: Standard Deviation

\section{Acknowledgment}

First and foremost, I would like to express my deepest gratitude to my advisors Professor Tefera Belachew and Mrs. Tizta Tilahun for their unreserved supports and guidance throughout the whole process of this work.

I would also like to thank Jimma University department of population and family health for giving an opportunity to conduct this study.

Officials working in Pawe Woreda Educational Bureau and respective schools deserve acknowledgement for their cooperation.

Last but not least, I would like to acknowledge my spouse Sentayehu Desibel without whose encouragements and moral supports this study wouldn't have been materialized.

\section{References}

[1] International Planned Parenthood Federation (IPPF), "Understanding Adolescents, in An IPPF Report on Young People's Sexual and Reproductive Health Needs," London. 1994. Available: http://www.plannedparenthood.org.

[2] Washington, D.C, "World's Youth Data Sheet," USA, Washington, D.C. $2006 . \quad$ Available: http://www.prb.org/pdf06/06WorldDataSheet.pdf

[3] Z. Fekadu and P. Kraft, "Predicting intended contraception in a sample of Ethiopian female adolescents," The validity of the theory of planned behavior. Psychology and Health, 2001; 16(2):207-222.
[4] Child and Adolescent Health and Development) 2004:1-2. Adolescent sexual and Reproductive Health. Html 2004

[5] Ministry of Health (MOH), "Rapid assessment on knowledge, Attitude and practices related to reproductive health in Ethiopia," Health education center and National office of population, Addis Ababa, Dec. 2000.

[6] F. Eshetu, D. Zakus and D. Kebede. "The attitude of students, Parents and Teachers towards the promotion and provision of condoms for adolescents in Addis Ababa," Ethiop. J. Health Dev. 1997; 11(1): 7-16.

[7] WHO, "Programming for adolescent health and development. Report of WHO/UNFPA/ UNICEF study group on health programming for adolescents," Technical report series No. 886. WHO, Geneva, 1999 Available: http://www.un.org/womenwatch/daw/vaw/.

[8] L. Meschke, S Bartholomae; R. Zentall, "Adolescent Sexuality and Parent-Adolescent Processes," Promoting Healthy Teen Choices. Family Relation. 2000; 49(2):143-154.

[9] Central Statistical Authority, "Demographic and Health Survey,” Addis Ababa, Ethiopia, 2005.

[10] E. Lemma, "Predictors of HIV/AIDS related Sexual behavior of high school adolescents based on the classical health behavior models," Jimma Town, South West Ethiopia. (Unpublished Thesis Addis Ababa University), December 2000 .

[11] UNICEF, UNAIDS and WHO, "Young people and, HIV/AIDS," Opportunity in crisis. Geneva. WHO, 2002.

[12] Reproductive Health Outlook (RHO), "Adolescent Reproductive health: Overview and Lessons Learned". Available at: http;//www.rho.org/html/adol-overview.htm (accessed on 11/30/03)

[13] G. Desalegn, F. Mesganaw, "Assessing communication on sexual and reproductive health issues among high school students with their parents," Bullen Woreda, Benishangul Gumuz Region, North West Ethiopia, Ethiop. J. Health Dev. 2010; 24 (2):89-95.

[14] A. Telto, "Assessment of Sexual Activity and Condom Utilization among Preparatory School Youths," Aleta Wondo Town, Sidama Zone 2009. (Unpublished thesis at A.A University)

[15] R. Adamu, M. Samuel and S. Ingidushet, "Patterns and correlates of sexual initiation, sexual risk behaviours, and condom use among secondary school students in Ethiopia". Ethiop. Med. J. 2003; 41(2): 163-177.

[16] I. Nassir, "Factors that influences school adolescents exposure to HIV/STD in Bale," Oromia Region, 2006. (Unpublished thesis at Addis Ababa University)

[17] A. Anemaw, "Assessment of sexual risk behaviours of inschool youth: effect of living arrangement of students," West Gojam zone, Amhara Regional State, Ethiopia, 2009. (Unpublished thesis at Addis Ababa University)

[18] M. Anteneh, "Reproductive health risk and sexual behaviour among school adolescents in Mojo preparatory and high school," East Shewa, Oromia region, 2008. (Unpublished thesis at Addis Ababa University) 
[19] A. Kidane, "Sexuality, perception of HIV/STI and condom use among high school adolescents in South Gondar administrative Zone," Amhara Regional State; 2004 (Unpublished thesis at Addis Ababa University)

[20] L. Ikamba and B. Ovedraogo, "High-risk sexual behaviour: knowledge, attitudes and practice among youth at kichangan ward," Tanga, Tanzania. Action research reports. 2003.
[21] Birhanu Alemu, Asrat Demessie, Atsede Fantahun, Kahsu Gebrekirstos. Awareness of Post-Exposure Prophylaxis of HIV Among Health Care Personnel in Asella Teaching Hospital, Asella Town, South-East Ethiopia, 2014: Cross Sectional Study. Clinical Medicine Research. Vol. 4, No. 3, 2015, pp. 69-74.

[22] Mesert Girma, Zewdu Shewangizaw, Getabalew Endazenaw. Assessment of Hiv Sero-Prevalence among St. Marry University Students, Ethiopia. Science Journal of Public Health. Vol. 3, No. 4, 2015, pp. 468-477. 